\title{
O léxico como reflexo de comportamento social: o caso do Caminho de Santiago no Atlas Linguístico do Maranhão
}

\author{
The lexicon as a reflection of social behavior: the case of Caminho de Santiago in \\ Linguistic Atlas of Maranhão \\ Luís Henrique SERRA* \\ Universidade Federal do Maranhão (UFMA) \\ Theciana Silva SILVEIRA** \\ Universidade Federal de São Carlos (UFScar)
}

\begin{abstract}
RESUMO: No texto, é apresentada a diversidade lexical para o item 24 do questionário semântico-lexical do Atlas Linguístico do Maranhão (ALiMA), que trata da faixa de estrelas que aparece no céu em dias estrelados e que é comumente conhecida como Via-Láctea. Levanta-se a hipótese de que a nova geração não reconhece mais o fenômeno natural por conta de mudanças de hábitos modernos e, por isso, o conhecimento popular sobre o fenômeno tende a desaparecer já que as novas gerações não o reconhecem. Esse movimento está registrado no léxico e pode ser observado nos dados catalogados pela equipe do ALiMA. O estudo tem como base teórico-metodológica a Dialetologia, a Geolinguística e a Lexicologia. Os dados coletados mostram que os indivíduos jovens não reconhecem a denominação e alguns idosos reconhecem, o que aponta um novo comportamento da sociedade que se reflete no léxico.
\end{abstract}

PALAVRAS-CHAVE: Léxico. Caminho de Santiago. Maranhão.

\begin{abstract}
In this text, the lexical diversity for item 24 of the semantic-lexical questionnaire of the Linguistic Atlas of Maranhão (ALiMA) is presented, which deals with the strip of stars that appears in the sky on starry days and is commonly known as the Milky Way. The hypothesis is that the new generation no longer recognizes the natural phenomenon due to changes in modern habits and, therefore, popular knowledge about the phenomenon tends to disappear since the new generations do not recognize it. This movement is registered in the lexicon and can be observed in the data cataloged by the ALiMA team. The study is based on the theoretical and methodological Dialectic, Geolinguistics and Lexicology areas. The data collected show that young individuals do not recognize the denomination and some elderly people do. This points to a new behavior in society that is reflected in the lexicon.
\end{abstract}

KEYWORDS: Lexicon. Caminho de Santiago. Maranhão.

\footnotetext{
Doutor em Letras pela Universidade de São Paulo, é professor-permanente do Programa de PósGraduação em Letras da Universidade Federal do Maranhão, campus Bacabal - MA. Professorpesquisador do Projeto Atlas Linguístico do Maranhão (ALiMA). E-mail: luis.ufma@gmail.com Doutoranda em Linguística do Programa de Pós Graduação em Linguística, da Universidade federal de São Carlos (UFSCar), Professora-pesquisadora do Projeto Atlas Linguístico do Maranhão (ALiMA) São carlos - SP. E-mail: thecianasilveira@gmail.com
} 


\section{Introdução}

Neste texto, apresentamos a hipótese de que o comportamento social de uma comunidade pode ser observado no léxico da língua dessa comunidade a partir de presença/ausência de elementos léxicos. No texto, partimos da hipótese de que determinadas denominações desaparecem do léxico ou estão em pleno processo de arcaísmo por conta do desinteresse da comunidade pelo fenômeno que é denominado por essa unidade do léxico. Nesse sentido, o objetivo deste texto é demonstrar, a partir de dados de fala maranhense, que o fenômeno atmosférico Via-Láctea não é mais objeto de interesse de um comunidade que se constitui a partir de um conjunto de fatores sociais (jovens, mais urbanos, com acesso à tecnologias digitais e de internet e com um tempo de escolaridade maior) e isso se revela no léxico desse grupo, que é escasso em denominações para esse fenômeno, quando não, é confundido com outros fenômenos atmosféricos mais conhecidos.

Para tentar provar nossa hipótese, consideramos dados semântico-lexicais do Atlas Linguístico do Maranhão (ALiMA), que está em fase de elaboração, com todos os inquéritos já finalizados. Neste trabalho, analisamos as unidades lexicais registradas nos inquéritos para a questão 24 do Questionário Semântico-Lexical (QSL), utilizado nos inquéritos do ALiMA (Numa noite bem estrelada, aparece uma banda ou faixa que fica no céu de fora a fora, onde tem muitas estrelas muito perto umas das outras. Como chamam esta banda ou faixa? ...). O Atlas Linguístico do Maranhão é um projeto ligado ao projeto Atlas Linguístico do Brasil (ALiB) e que é desenvolvido por uma equipe de pesquisadores da Universidade Federal do Maranhão (alunos da graduação, pósgraduação e professores da instituição) no Departamento de Letras. O projeto ALiMA se singulariza do ALiB por apresentar questões que são específicas da realidade do estado e que não são contempladas no Atlas do Brasil.

Escolhemos para a análise o item 24 do questionário semântico-lexical do ALiMA porque ele exemplifica com clareza o fenômeno da modernidade na atualidade e como o homem tem substituído conhecimentos tradicionais por conhecimentos considerados "modernos". Como se sabe, os povos antigos utilizavam a astrologia ou o conhecimento dos astros para organizar suas vidas e para fazer grandes viagens, o que proporcionou as grandes navegações e, consequentemente, o desenvolvimento do mundo moderno. Nesse sentido, é importante lembrar o espaço que determinados 
saberes tinham na sociedade, visto que, até certo tempo, “(...) a filosofia, a "ciência, magia e religião não constituíam domínios separados e os alquimistas eram chamados "filósofos"” (ZORDAN, 2013, 157, grifo original). Até certo tempo da modernidade recente, observamos uma importante necessidade do conhecimento sobre os astros, conhecimento que interferia no destino e na posição do homem na sociedade. Nesse sentido, Zordan (2013, p. 157) comenta que

No Renascimento, o saber estava intricado nas analogias da forma mágica de pensar, cuja ocupação era identificar as semelhanças para melhor entender e lidar com a Natureza. A sabedoria é concebida como capacidade de decifrar as similitudes invisíveis entre os astros, as estrelas, os minerais, as plantas, os animais, as horas do dia, as épocas do ano e as partes do corpo humano.

No entanto, o que se tem observado é que o conhecimento dos astros tem recebido tratamento secundário por parte da sociedade pós-moderna, sendo, muitas vezes, relegado ao conhecimento dos signos do zodíaco, sobre os quais se tem bastante especulações e crendices. A sociedade pós-moderna tem apresentado características de um universo mais digital, substituindo tecnologias analógicas por tecnologias remotas e online. Com a globalização e o acesso a recursos tecnológicos mais avançados, o homem tem deixado de utilizar recursos naturais, fenômenos da natureza e outros eventos ligados à natureza para obter informações sobre o universo e o tempo. É interessante também pensar, nesse sentido, como a tecnologia tem levado o homem a mudar sua relação com a natureza, visto que, embora conte com as mudanças da natureza no seu planejamento diário (o que fica claro quando consulta aplicativos de temperatura e condições climáticas para fazer viagens, festas e outros eventos), não tem mais um interesse maior como os povos antigos, as antigas gerações. No passado, o conhecimento da natureza e dos fenômenos do céu, mar e terra era muito mais importante na vida sociocultural dos povos, o que tem se perdido por conta de uma modernidade com características muito particulares, dentre elas, o desinteresse pelo modo antigo de viver e de se relacionar com a realidade física e cultural.

Nesse contexto, o conhecimento sobre as constelações e, em especial, sobre o reconhecimento da Via-Láctea ou o caminho de Santiago no céu são exemplos de como a tradição tem sofrido apagamentos da memória social, devido ao fenômeno da modernidade e da tecnologização da sociedade. 
O nome Caminho de Santiago, dado à Via-Láctea, provavelmente tenha origem na tradição portuguesa que está ligada às estrelas e outros astros e que tem uma certa representatividade dentro da cultura do Brasil. Dar nomes aos astros e às constelações é muito comum entre os povos conquistados pelos portugueses e espanhóis, e nasce da relação que esses povos tinham com o mar e com as estrelas, utilizadas como guias nas grandes navegações. A figura de São Tiago é também muito forte por conta de uma série de lendas e histórias ocorridas ao longo da formação de Portugal. Segundo a tradição religiosa portuguesa, o apóstolo de Cristo teria ido a Europa, em Coimbra, e pregado o evangelho pela região. "De acordo com a tradição cristã, após a morte de Cristo e a dispersão dos Apóstolos pelo mundo, Santiago foi pregar em regiões longínquas, passando algum tempo a tentar evangelizar a Península Ibérica, em especial na região da Galiza." (MENDES, 2009, p. 1).

Algumas versões dessas histórias contam que o apóstolo ajudou na libertação dos Mouros, no século I d.C. (GUIMARÃES, 2008). De acordo com Cunha (s/d apud DUARTE, 2016), a devoção a Santiago existe desde há muitos séculos, sendo o apóstolo considerado o Patrono da Reconquista. A primeira peregrinação em Portugal na região que ficou conhecida como Santiago teria sido conquistada por Fernando Magno em 1064. Este pedira ajuda ao apóstolo na conquista de Coimbra, tendo depois realizado a peregrinação como promessa e agradecimento após Coimbra ter sido efetivamente conquistada. A partir desses e de outros elementos da cultura e da história portuguesa, observa-se que a presença da figura de São Tiago no imaginário português é muito forte e, com a vinda dos portugueses ao Brasil, acabou marcando presença no Brasil por meio dos costumes, cultura e crendices.

Considerando que o léxico resulta de um saber partilhado "que existe na consciência dos falantes de uma língua" (OLIVEIRA; ISQUERDO, 2001, p.9), neste texto, analisaremos as denominações dadas à faixa de estrelas estendida no céu de fora a fora, que aparece nos dias de céu estrelado e que tem a ver com a tradição portuguesa no Brasil. Nesse sentido, o texto é constituído pela presente introdução; algumas questões acerca da dialetologia e da sociolinguística; considerações sobre a metodologia de recolha de dados que norteou o presente estudo, além de apresentar os dados do Maranhão com relação à questão 24 do questionário Semântico-lexical do ALiMA. Por fim, serão apresentadas algumas considerações sobre as denominações encontradas, 
além de algumas ausências sobre esse tema entre as respostas na fala dos informantes maranhenses. O texto se encerra com a apresentação das considerações gerais deste estudo, seguidas das referências bibliográficas citadas e que basearam o estudo.

\section{Atlas Linguísticos e o registro do léxico}

\subsection{A Dialetologia e a Geolinguística}

Inserida no campo da Linguística, a Dialetologia tem como objetivo descrever e analisar traços linguísticos dos falares de uma região, a priori, em sua dimensão espacial. A Geolinguística, por sua vez, é um campo da Linguística que se ocupa da elaboração do registro das formas linguísticas por meio de atlas linguísticos. Essas disciplinas ocupam-se do léxico, uma olhando sua diversidade e distribuição na sociedade e a outra com o registro dessa diversidade. Cumpre notar que a própria dialetologia iniciou-se com o registro do léxico. Nesse sentido, Cardoso e Mota (2000, p. 42) comentam que "As observações sobre o léxico constituem-se na primeira manifestação mais amplamente documentada de reconhecimento da diversidade lingüística em nosso país, e, no caso inicial, atestada entre o falar de Portugal e o falar brasileiro.".

Por meio de análise do léxico de uma determinada região ou de um país, é possível observar zonas dialetais que estão inter-relacionadas com a diversidade cultural e com a própria formação social e histórica desse povo. Ainda de acordo com Cardoso e Mota (2017, p. 8), “A diversidade que exibe o léxico de uma língua tem sempre uma grande amplitude, seja determinada por razões histórico-culturais, seja porque esse é o mundo da liberdade maior de criação do falante em face dos outros níveis (fonético e morfossintático).”. Embora o dicionário de língua registre o léxico e sua diversidade, esse instrumento ainda não registra integralmente e nem acompanha a dinamicidade do léxico das línguas naturais. Os Atlas Linguísticos, por outro lado, buscam registrar na fala de indivíduos oriundos das localidades, sem observar padrões ou modelos de denominações, as diferentes formas do léxico do modo que ele é utilizado pelas diferentes comunidades linguísticas. Nesse sentido, o léxico registrado nos Atlas Linguísticos, muitas das vezes, não é o léxico registrado no dicionário da língua, visto que o dinamismo com que o léxico se modifica é observado de longe pelos instrumentos 
oficiais da língua, e os atlas acabam por apresentar um registro mais atualizado com as modificações naturais do léxico.

Com as mudanças e os avanços na metodologia dos estudos dialetais, a Dialetologia ganhou novos espectros de interesses, surgindo, assim, uma perspectiva pluridimensional, que consiste em estudar, para além da dimensão espacial, fatores sociais diastráticos, diagenéricos, diageracionais, entre outros. Nesse sentido, Isquerdo comenta a importância de dados geolinguístico para a compreensão do léxico e sua realidade em uma língua natural.

\begin{abstract}
Os atlas linguísticos são de grande valia, pois fornecem dados confiáveis acerca do grau de disseminação de uma variante lexical, o que é garantido pela metodologia que orienta as pesquisas geolinguísticas, em especial o uso de questionário de natureza onomasiológica utilizado na coleta de dados de uma rede de pontos distribuída na área investigada - um município, um estado, uma região ou um país, dependendo da amplitude do atlas, ou seja, se de pequeno ou grande domínio. (ISQUERDO, 2007, p. 199)
\end{abstract}

Considerando a realidade e a importância e a metodologia tanto da Dialetologia quanto da Geolinguística, optamos pela recolha de dados de um atlas linguístico para observar de que modo as diferentes regiões do Maranhão, os sexos e as gerações do Estado têm registrado o fenômeno de observação da Via-Láctea e de que modo o Estado tem registrado esse fenômeno no seu acervo lexical.

\title{
2.2 Atlas Linguístico do Maranhão: constituição do corpus
}

Neste trabalho, buscamos analisar as denominações encontradas para o item lexical caminho de Santiago bem como a presença/ausência dessas denominações nas localidades investigadas pelo ALiMA. O Atlas Linguístico do Maranhão está sendo constituído a partir de dados de 16 municípios distribuídos pelas cinco mesorregiões do Estado, a saber:

- Mesorregião Norte: São Luís, Raposa e Pinheiro.

- Mesorregião Central: Bacabal e Tuntum.

- Mesorregião Oeste: carutapera, Turiaçu e Imperatriz.

- Mesorregião Leste: Brejo, Caxias, Codó, São João dos Patos e Araioses.

- Mesorregião Sul: Carolina, Alto Parnaíba e Balsas. 
$\mathrm{Na}$ Figura 1, para melhor observação, apresentamos a distribuição dessas localidades investigadas no mapa do Estado.

Figura 1. Rede de distribuição de pontos do ALiMA

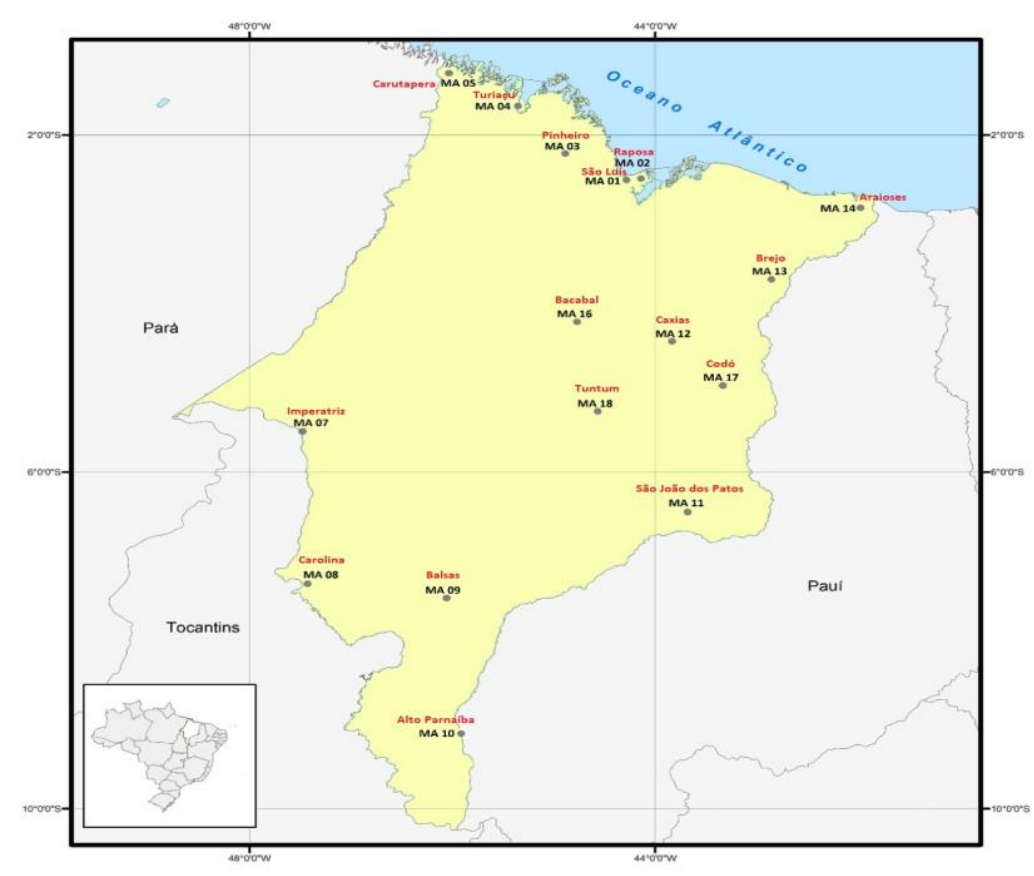

Fonte: Projeto ALiMA

Para cada localidade, foram selecionados 4 (quatro) informantes, exceto a capital, São Luís, onde foram considerados 8 (oito) informantes. Trata-se de 68 informantes no total que responderam à questão 24 (Numa noite bem estrelada, aparece uma banda ou faixa que fica no céu de fora a fora, onde tem muitas estrelas muito perto umas das outras. Como chamam esta banda ou faixa?...) do QSL, inserido no campo semântico Astros e Tempo. Esses informantes estão distribuídos igualmente, seguindo a metodologia do Projeto ALiMA, de acordo com os seguintes critérios de: (i) idade faixa etária I, entre 18 e 30 anos, e faixa etária II, entre 50 a 65 anos; (ii) sexo - homens e mulheres; (iii) escolaridade - Ensino Fundamental, até a $4^{\text {a }}$ série, e Ensino Superior completo, este último nível considerado apenas para a capital; e (iv) naturalidade informantes nascidos e criados nas localidades investigadas.

Para catalogação dos dados utilizados neste estudo, foram feitas transcrições grafemáticas dos inquéritos, e as unidades lexicais foram organizadas em uma tabela excel; em seguida, partimos para as análises dos dados que apresentamos a seguir. 


\section{O Caminho de Santiago no Maranhão: memórias de um povo}

Caminho de Santiago é uma das denominações atribuídas à Via-Láctea, que, segundo o dicionário Caldas Aulete (2011, p. 1411), é a "faixa luminosa visível no céu noturno limpo de nuvens, que é a visão das estrelas e corpos celestes que são parte da galáxia da Via Láctea, à qual pertence o sistema solar e o planeta Terra.”. É costume no nordeste quase todo, em noites estreladas, com poucas nuvens, observar a faixa de estrelas que é denominada de via-láctea e que, segundo a tradição portuguesa, é o caminho de Santiago, santo católico, um dos apóstolos de Cristo. No entanto, embora o dicionário tenha preferência pela forma via-láctea, na fala de indivíduos do Maranhão, que participaram do inquérito do ALiMA, a denominação não aparece. Em seu lugar, algumas outras têm a preferência dos falantes.

É válido lembrar que o conjunto dessas denominações faz parte de um repertório cultural/religioso do estado do Maranhão e, desse modo, o uso da denominação implica na interação entre dois elementos importantes da identidade do Maranhão: línguacultura. Cada povo tem seu modo de nomear as entidades presentes no universo; em se tratando da cultura brasileira, podemos perceber de forma evidente as heranças europeias, mas não podemos esquecer as culturas que já se faziam presentes no Brasil antes mesmo da chegada dos povos europeus.

Nas sociedades antigas, a observação do céu esteve na base do conhecimento, pois era por meio do céu que certos fenômenos poderiam ser explicados, como dia e noite, as fases da lua, as estações do ano, bem como outros saberes. Quando pensamos nos índios, antes da colonização, é importante atentarmos para as línguas indígenas e os traços culturais que dependiam da natureza e dos fenômenos que nela aconteciam. No trabalho feito por Claude d'Abbeville (1614), o missionário francês passou quatro meses com os Tupinambás no Maranhão e registrou cerca de 30 estrelas e constelações. Segundo o pesquisador de astronomia Germano Afonso,

\footnotetext{
os índios brasileiros davam maior importância às constelações localizadas na Via Láctea, que podiam ser constituídas de estrelas individuais e de nebulosas, principalmente as escuras. A Via Láctea é chamada de Caminho da Anta (Tapi'i rapé, em guarani) pela maioria das etnias dos índios brasileiros, devido principalmente às constelações representando uma Anta (Tapi'i, em guarani) que nela se localizam. (AFONSO, s/d)
} 
Considerando essa realidade, podemos perceber que a necessidade de usar o céu e seus astros como orientação se deu, sobretudo, nos primórdios quando o homem ainda não tinha tecnologias e outros meios de obter conhecimento. Afonso (s/d), ainda, ressalta que esse conhecimento está sendo perdido pelas gerações em consequência do rápido processo de globalização e a dificuldade de se registrar, proteger e difundir esses conhecimentos. Nesse sentido, são de fundamental importância esses registros em banco de dados, que podem ser armazenados nos atlas linguísticos, por exemplo.

Para o item investigado, em relação à questão 24 do QSL, foram registradas sete designações diferentes, a saber: Carreirão de Santiago, Caminho de Santiago, Caminho de São Gonçalo, Cordão de Nossa Senhora, Nuvem, Sete estrelas, Nove Ave-Maria. Dentre elas, a designação mais frequente é Caminho de Santiago com 10 ocorrências.

Considerando a diversidade lexical encontrada na questão 24 do questionário semântico-lexical do ALiMA e o perfil do informante do projeto, é possível fazer uma análise pluridimensional do fenômeno da variedade lexical. Dessa forma, analisamos questões de natureza semântico-lexical, diageracional e diatópico por pensarmos que o fenômeno da diversidade lexical para esse item está ligado a fatores linguísticos, de geração e localidade.

\subsection{A diversidade lexical do caminho de Santiago: aspectos}

$\mathrm{O}$ quadro 01 sintetiza a diversidade lexical para denominar a faixa de estrelas que aparece no céu em dias estrelados. No quadro, pode ser observado, de modo geral, o número de respostas válidas dadas à questão 24. Consideramos respostas válidas ou obtidas às denominações recorrentes na localidade (dada por mais de 2 informantes), as que foram explicadas pelo informante no momento do inquérito, sobretudo quando ele é indagado pelo inquiridor sobre a resposta dada, além de respostas que podem estar dicionarizadas. A categoria de respostas não-válidas ou não-obtidas reúne respostas como não sabe, não lembra ou respostas que os informantes dão como uma definição/explicação diferente da definição perguntada no inquérito.

Organizamos os dados para tentar mostrar aspectos linguísticos e nãolinguísticos. Passaremos a comentar algumas questões pertinentes da variação lexical encontrada. 


\subsection{Os números da variação lexical para Caminho de Santiago no Maranhão}

No Quadro 01, apresentaremos a distribuição de ocorrências de respostas obtidas e não-obtidas. Na primeira coluna, trazemos a mesorregião, na coluna seguinte, as localidades investigadas, e nas terceiras e quartas, as faixas etárias I e II, respectivamente, apresentando o número de respostas obtidas e não-obtidas. O quadro não trata de questões de variação lexical, mas sim da quantidade de informantes que conhecem o item em questão na pergunta 24 do questionário semântico-lexical do ALiMA. Após a apresentação dos dados sobre o reconhecimento ou não da questão por parte dos informantes, passaremos a discutir a variação lexical e suas implicações nãolinguísticas. Com base no Quadro 1, podemos observar a presença/ausência de respostas como fundamentais para entender a presença/ausência de denominações para o fenômeno estrelar Caminho de Santiago no Maranhão.

Quadro 01. Distribuição de ocorrências de respostas e não-respostas para o caso caminho de Santiago

\begin{tabular}{|c|c|c|c|c|c|}
\hline \multirow[b]{2}{*}{ MESORREGIÃO } & \multirow[b]{2}{*}{ LOCALIDADE } & \multicolumn{2}{|c|}{ FAIXA ETÁRIA I } & \multicolumn{2}{|c|}{ FAIXA ETÁRIA II } \\
\hline & & OBTIDAS & $\begin{array}{c}\text { NÃO } \\
\text { OBTIDAS }\end{array}$ & OBTIDAS & $\begin{array}{c}\text { NÃO } \\
\text { OBTIDAS }\end{array}$ \\
\hline \multirow{3}{*}{ NORTE } & São Luís & 0 & 4 & 1 & 3 \\
\hline & Raposa & 0 & 2 & 0 & 2 \\
\hline & Pinheiro & 0 & 2 & 1 & 1 \\
\hline \multirow{2}{*}{ CENTRO } & Bacabal & 0 & 2 & 0 & 2 \\
\hline & Tuntum & 0 & 2 & 1 & 1 \\
\hline \multirow{3}{*}{ OESTE } & Carutapera & 0 & 2 & 1 & 1 \\
\hline & Turiaçu & 2 & 0 & 2 & 0 \\
\hline & Imperatriz & 0 & 2 & 2 & 0 \\
\hline \multirow[b]{2}{*}{ LESTE } & Brejo & 0 & 2 & 1 & 1 \\
\hline & Caxias & 0 & 2 & 1 & 1 \\
\hline
\end{tabular}




\begin{tabular}{|c|c|c|c|c|c|}
\hline & Codó & 0 & 2 & 1 & 1 \\
\hline & São João dos Patos & 0 & 2 & 1 & 1 \\
\hline & Araioses & 0 & 2 & 0 & 2 \\
\hline \multirow{3}{*}{ SUL } & Carolina & 1 & 1 & 1 & 1 \\
\hline & Alto Parnaíba & 1 & 1 & 2 & 0 \\
\hline & Balsas & 0 & 2 & 1 & 1 \\
\hline \multicolumn{2}{|c|}{ TOTAL } & 4 & 30 & 16 & 18 \\
\hline
\end{tabular}

Fonte: Projeto ALiMA

Como é possível observar no quadro 01, o conhecimento sobre o item em questão é bastante diferente nos dois grupos investigados. O número de não-resposta ou não obtidas entre as duas faixa-etárias investigadas é muito expressivo, o que mostra como o item em questão não faz mais parte do interesse diário da maioria dos informantes entrevistados. É curioso observar que mesmo na segunda faixa-etária, em que se observa um número maior de respostas obtidas, é comum indivíduos dessa faixa não conhecerem ou não saberem do que se trata quando perguntado sobre o fenômeno do caminho de Santiago. Para melhor ilustrar os dados dessa questão no Maranhão, elaboramos alguns gráficos que nos permitem observar mais de perto as questões imbricadas nessa variação. O Gráfico 1, a seguir, sintetiza o quadro 1 e mostra o percentual de respostas não-válidas ou não obtidas em comparação com as válidas/obtidas.

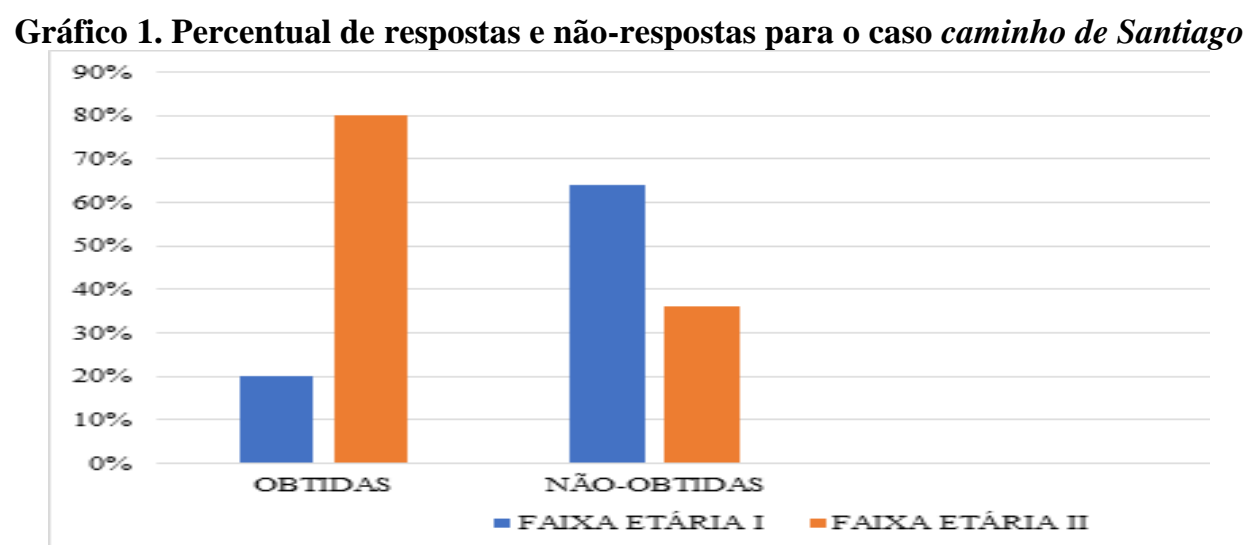

Fonte: Projeto ALiMA 
De acordo com os dados apresentados, é possível observar que há uma significante diferença de percentual no que tange às respostas obtidas na faixa etária I, em relação à faixa etária II. Só $20 \%$ dos informantes jovens respondeu à questão 24 , contrastando com os $80 \%$ das respostas dos informantes mais velhos. Em relação às respostas não-obtidas, a faixa etária I apresenta um percentual maior, com 62,5\%, enquanto a faixa etária II apresenta um percentual menor, com 37,5\%. Esses dados revelam que o conceito do item lexical Caminho de Santiago não é conhecido pelo público mais jovem e, quando conhecem, não sabem como é chamado. No comput geral dos dados, das 68 respostas obtidas na aplicação do questionário, 20 foram consideradas como respostas válidas, enquanto que 48 respostas foram de não lembra, não sabe e respostas que não correspondem ao item investigado. A exemplo de resposta não válida, o trecho a seguir mostra, na fala de um informante da primeira faixa etária, um exemplo desse tipo de resposta.

INQ: Numa noite bem estrelada, aparece uma banda ou faixa que fica no céu de fora a fora, onde tem muitas estrelas muito perto umas das outras. Como chamam aquilo?

INF: Não sei.

INQ: Tu já viste? Elas fazem tipo uma faixa, ficam bem juntinhas...

INF: Não, ainda não olhei não.

(INFORMANTE MULHER, $1^{\text {a }}$ FAIXA ETÁRIA)

O gráfico 02 , a seguir, traz os itens lexicais considerados válidos, mostrando o grupo de variantes encontradas para a questão 24 do questionário semântico-lexical do ALiMA.

Gráfico 2. Variantes do item lexical da questão 24

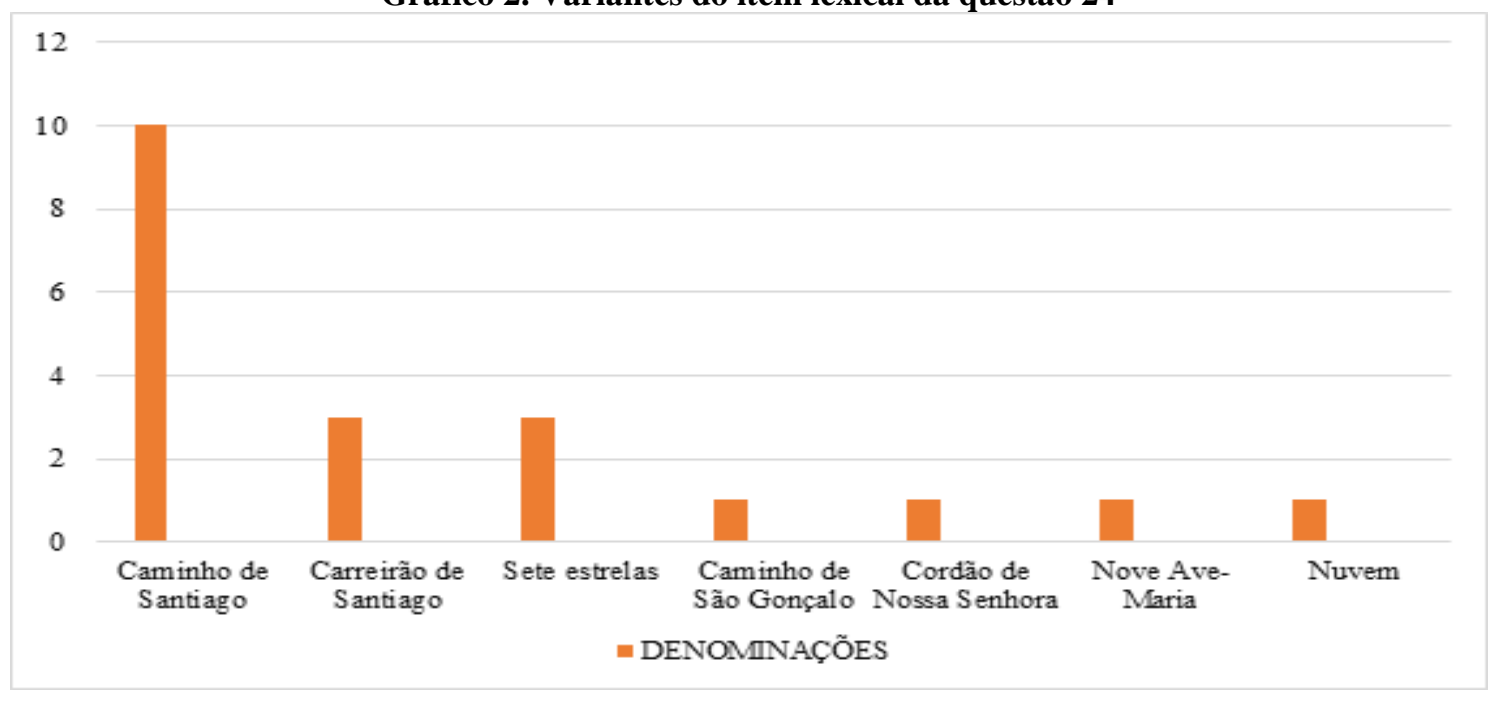

Fonte: Projeto ALiMA 
No gráfico 2, observamos que a denominação Caminho de Santiago é a mais comum entre os informantes, seguida de carreirão de Santiago e sete estrelas. Algumas denominações aparecem apenas uma vez e que estariam relacionados com o item. A denominação Caminho de Santiago é a forma mais popular da Via-Láctea e, como se observou, está relacionado com a cultura católica portuguesa. No mesmo sentido, temos o Carreirão de Santiago, em que apenas o elemento nuclear do sintagma se modificou por um outro que tem o mesmo sentido de "caminho". O dicionário Houaiss da Língua Portuguesa (HOUAISS E VILLAR, 2009, eletrônico) afirma que a forma carreirão é o aumentativo de carreiro, que apresenta acepção "lugar em que geralmente animais de caça passam", além de "caminho estreito, atalho". A denominação sete estrelas se refere a outro fenômeno cósmico, que é a constelação de plêiade (1 astr conjunto de estrelas da constelação de Touro; sete-estrelas [Seis delas são visíveis a olho nu, mas o conjunto inteiro tem centenas de estrelas. (HOUAISS E VILLAR, 2009, eletrônico); essa resposta foi validada porque, apesar da insistência dos inquiridores, os informantes confirmaram que se tratava do fenômeno investigado. O trecho que segue, retirado de um inquérito feito no município de Caxias, no Maranhão, mostra como a forma sete estrelas tem sido entendida como o Caminho de Santiago.

INQ: Numa noite bem estrelada, aparece uma banda ou faixa que fica no céu de fora a fora, onde tem muitas estrelas muito perto umas das outras, como é que se chama essa faixa, essa banda assim no céu?

INF. - Sete estrelas

INQ. - Mas sete estrelas tem só sete ou tem mais estrelas? Porque essa tem muitas estrelas bem pertinho...

(...)

INQ. - Não, é que eu quero saber como vocês chamam aqui em Caixas. Tem uma faixa assim, de fora a fora, mas muitas estrelas... porque a senhora disse sete estrelas, num é? Aí eu tô perguntando, esse sete estrela, tem só sete ou tem muitas, muitas estrelas?

INF. - São muitas, muitas estrelas, bem pertinha e fica assim, como que tá piscando.

(INFORMANTE MULHER, $2^{\mathrm{a}}$ FAIXA-ETÁRIA)

Com relação a esse item, pode-se pensar que esteja ocorrendo uma simplificação ou uma generalização na denominação desses dois fenômenos, já que o aspecto que os diferencia é a quantidade de estrelas possíveis de serem observadas pelo informante. As formas Caminho de São Gonçalo, Cordão de Nossa Senhora, Nove Ave-Maria seriam corruptelas do nome Caminho de Santiago, visto que todos têm por base a tradição da 
religião portuguesa católica, possível campo de origem da denominação. Além disso, o aspecto da forma (observado também em nuvem) é entendido como importante, visto que o aspecto longilíneo da Via-Láctea, quando observada da terra, autoriza pensar em uma linha, um caminho, o que pode ter dado origem às denominações cordão e nove ave-Maria, uma clara alusão ao rosário, utilizado nos cultos católico-cristãos. A denominação nuvem, por sua vez, pode ser motivada pelo aspecto nebuloso da ViaLáctea quando ela é observada sem instrumentos de observação avançados da terra.

Um outro aspecto que chama a atenção é o aspecto da distribuição sóciogeográfica da variação. Cardoso, sobre esse aspecto, comenta que "O vazio geográfico é denunciador de informações as mais diversas e pertinentes para o confronto linguístico, do mesmo modo que o registro de usos.”. (CARDOSO, 2010, p. 15). Observando o quadro 1, apresentado anteriormente, a incidência de respostas válidas nas localidades mais urbanas do Estado é muito menor do que em localidades consideradas mais rurais. Por exemplo, os municípios de São Luís (norte), Imperatriz (oeste) e Balsas (sul), municípios populosos e com um expressivo poderio econômico no Maranhão, apresentam um índice muito pequeno de respostas válidas. Os três municípios investigados somam um total de 16 respostas, sendo que 4 foram consideradas válidas e 12 não-válidas. É curioso observar, ainda, que todas as respostas válidas foram dadas por indivíduos da segunda faixa-etária, o que nos permite levantar a hipótese de que localidades urbanas têm um comportamento menos vigilante com relação ao tempo, ou a relação com a natureza e seus fenômenos é menor, visto que a tecnologia tem tomado espaço nos costumes e na cultura dessas localidades. Em contraponto aos resultados apresentados pelos três municípios mais ricos ou populosos do Maranhão, a análise mostra que em comunidades menos urbanas, como Alto Parnaíba (sul), Turiaçu (oeste) e Pinheiro (norte) apresentam 12 respostas, sendo 6 válidas ou obtidas e 6 não-válidas ou não-obtidas, com o detalhe de que 3 dessas respostas foram dadas por indivíduos da primeira faixa-etária, o que não ocorre nos municípios mais desenvolvidos economicamente.

Diante dessa diversidade lexical e dos dados apresentados até aqui, é possível, em primeira análise, associar o não conhecimento das formas linguísticas por parte dos informantes da primeira faixa-etária às questões ligadas ao modo de vida da própria faixa etária dos informantes jovens, pois a geração mais nova não tem o hábito de 
observar os fenômenos da natureza como os mais antigos, que buscavam orientação por meio da observação do céu. Isso se dá pelo fato de que esses hábitos e costumes fazem parte dos aspectos culturais que estão diretamente relacionados à prática de vida social moderno. Logo, a não prática da busca por informações ou observação dos céus leva ao desaparecimento desse conhecimento e, consequentemente, da sua nomeação.

Para além do esquecimento da memória cultural, a escassez de acervos lexicais que abarquem esse conhecimento popular corrobora para esse cenário. Por esse motivo, se torna evidente a necessidade de trabalhos como a elaboração de Atlas Linguísticos e dicionários que representem e abranjam os regionalismos, acompanhando as variações e mudanças da língua/cultura.

Cabe ainda, em uma segunda análise, trazer à tona o constante contato da prática social por meio das tecnologias. Atualmente, com o grande avanço da globalização, o grande uso de tecnologias tem mudado a forma de enxergar o mundo e de se relacionar com ele. Por exemplo, para saber sobre a previsão do tempo ou outro fenômeno que envolva a natureza, com apenas um clique a informação chega ao usuário de aplicativos, sites de informações, não sendo mais necessária a observação do céu, prática essa bastante utilizada pelos povos primitivos desde a Antiguidade que vem se perdendo com o passar dos séculos com o surgimento de novos veículos de comunicação/informação.

Isso nos revela que estudar a língua em seus contextos reais é de fundamental importância, como já salientado, língua e cultura são indissociáveis, logo, podemos inferir que isso ocorre porque a geração mais jovem está mais adepta às tecnologias, e, com esses grandes avanços, não necessitam buscar informações na natureza. A ausência ou presença de denominações, além de um número considerado de respostas nãoválidas, é reflexo dessa mudança na sociedade, nas novas gerações do Maranhão.

Portanto, é de suma importância destacar que, embora haja um grande número de resposta não-obtida, a não-resposta também nos revela sobre os fatos da língua e da cultura de um povo; desse modo, o interesse não está somente na presença dos registros dos dados, mas também na ausência deles. É essa ausência que nos mostra o comportamento social no caso Caminho de Santiago, e é ele que nos aponta para os costumes da sociedade do Maranhão que tem deixado de lado aspectos da tradição para dar espaço para novos costumes e valores modernos. 


\section{Considerações Finais}

A pesquisa sintetizada neste texto partiu da hipótese de que o léxico registra a mudança de comportamento que ocorre no mundo, selecionando como exemplo os dados do questionário semântico-lexical, item 24, do Atlas Linguístico do Maranhão. Os dados nos permitiram observar que a análise do léxico, nível linguístico em que se refletem com nitidez a cultura, o comportamento e a realidade psicossocial dos falantes de uma língua natural, é um importante meio para a compreensão da sociedade e os movimentos que são naturais. Nesse sentido, evidencia-se mais uma vez a relação intrínseca entre a língua e a sociedade. Desse modo, fica evidente ainda que mudanças ocorridas nessa acarretam em mudanças ocorridas naquela. O caso da variação lexical e a presença e a ausência de denominações relacionadas com a observação da Via-Láctea, muito comum na cultura agrária, que ainda hoje depende do conhecimento da natureza para o sucesso do trabalho e do seu dia-dia, reforçam ainda mais a hipótese dessa relação entre língua e sociedade. A variação lexical para esse item demonstra também que, embora pequena, essa cultura de observação do céu tem espaço dentro de uma sociedade mais agrária, visto que os indivíduos dessas comunidades tendem ainda a reconhecer esse item, enquanto que regiões mais industriais tendem a não conhecer ou esquecer esse fenômeno da natureza.

Portanto, trabalhos como este são de fundamental importância para o registro e o armazenamento desses conhecimentos populares que são passados de geração em geração, mas que estão sendo perdidos ao longo do tempo. Acervos lexicais e trabalhos desenvolvidos acerca desses fenômenos corroboram para preservação não só do registro vocabular, mas também de toda uma prática que envolve hábitos, costumes que fazem parte da cultura do povo maranhense.

\section{REFERÊNCIAS}

AFONSO, G. B. As constelações indígenas brasileiras. Observatórios Virtuais. Disponível em: 〈http://www.pindorama.art.br/file/constelacoesindigenasguarani.pdf $>$. Acesso em: 07/01/ 2020.

CALDAS AULETE. Novíssimo Aulete: dicionário contemporâneo da Língua Portuguesa. Rio de Janeiro: Lexikon, 2011. 
CARDOSO, S. A. Geolinguística: tradição e modernidade. São Paulo: Parábola Editorial, 2010.

CARDOSO, M. A. M.; MOTA, J. A. Dialetologia brasileira: O atlas linguístico do Brasil. Revista Anpoll, n.8, p. 41-57, 2000.

CARDOSO, M. A. M.; MOTA, J. A. Estudos Geolinguísticos: caminhos seguidos no território brasileiro. Lingüística. v. 33, n.1, p. 1-20, 2017.

CLAUDE D'ABBEVILlE. Histoire de la Mission des Pères Capucins en l'Isle de Maragnan et terres circonvoisines. Paris: François Huby, 1614.

DUARTE, A. C. Fernandes. Caminhos de Santiago: o caminho português como fator de desenvolvimento turístico do conselho de Barcelos. 112fls. Dissertação (Mestrado em Turismo). Faculdade de Letras, Universidade do Porto, 2016.

GUIMARÃES, Waldinei Comercio de Souza. O crepúsculo em Santiago: a jornada do peregrino ruma à religiosidade e a descoberta analítica. 2008, 117fls. Dissertação (Mestrado em Ciências da Religião), Pontifícia Universidade Católica de São Paulo, 2008.

HOUAISS, A.; VILLAR, M. S. Dicionário Eletrônico Houaiss. Rio de Janeiro: Objetiva, 2009.

ISQUERDO, A. N. A propósito dos dicionários de regionalismos no português do Brasil. In: ISQUERDO, A. N.; ALVES, I. M. (Orgs.). As ciências do léxico: lexicologia, lexicografia e terminologia.Vol. III. Campo Grande: UFMS, São Paulo: Humanitas, 2007. p.139-208.

OLIVEIRA, A. M. P. P. de; ISQUERDO, A. N. Apresentação. In. (orgs). As ciências do léxico: lexicologia, lexicografia e terminologia. $2^{\mathrm{a}}$ ed. Campo Grande: EDUFMS, 2001, p. 9-11.

MENDES, A. C. Peregrino a Santiago de Compostela: uma etnografia do caminho português. 80fls. Dissertação (mestrado em Antropologia Social e Cultural), Instituto de Ciências Sociais, Universidade de Lisboa, 2009.

ZORDAN, P. B. G. Os saberes mágicos do início da modernidade. Revista Teias, v. 14, n. 33, p. 157-167, 2013. 